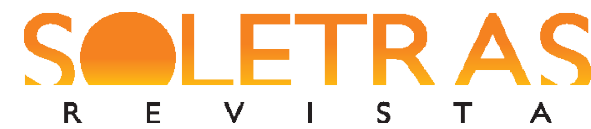

\section{A poesia excêntrica de Medeiros e Albuquerque: o decadentismo na Academia}

\author{
Irineu Eduardo Jones Corrêa ${ }^{1}$
}

\begin{abstract}
Resumo: Este trabalho aborda a presença da poesia decadentista no campo literário brasileiro, com foco especial no trabalho de José Joaquim de Medeiros e Albuquerque (1867-1934), um jovem poeta que publica seus dois livros com menos de 23 anos de idade. Seus poemas daquele período são pouco conhecidos e, quando comentados são tratados de modo secundário, embora o autor tenha se consagrado como jornalista, conferencista, crítico literário, contista e cronista, memorialista, filólogo, autor da reforma ortográfica de 1907 e estado no grupo fundador da Academia Brasileira de Letras. A hipótese desenvolvida aqui é a de que essa recepção não considera a retórica e os rituais da época e do modelo decadentista. Ao proceder a uma reaproximação de sua obra a partir destes parâmetros, observa-se que sua poesia amplia suas dimensões, revelando-se um trabalho perfeitamente engajado em seu tempo e na estética decadentista. Os procedimentos de leitura e síntese propostos aqui são baseados na análise do discurso, conforme desenvolvida por Dominique Maingueneau, e nos estudos sobre a organização dos sistemas simbólicos de Pierre Bourdieu.
\end{abstract}

Palavras-chave: Belle Époque. Decadentismo. Esteticismo. Poema. Tribo.

\title{
Apresentação
}

A obra poética de Joaquim José Medeiros e Albuquerque (1867-1934) é um desses casos em que o sucesso pessoal posterior influencia a permanência das opiniões sobre o sujeito que escreveu na juventude. Essa influência é, entretanto, às avessas. Sendo uma obra cosmopolita, escrita em forte diálogo com as estéticas inaugurais da modernidade, assinada por um nome muitíssimo bem posicionado na tradição literária, ela se encontra num relativo ostracismo, sendo recepcionadas em que se leve em conta aquilo que ela oferece em sua proposta original, apresentada que foi no final da penúltima década do século XIX.

Tendo como corpus os dois primeiros livros do autor, ambos de 1889, ensaiaremos uma proposta de leitura que considere justamente o momento em que a obra foi produzida, embora nos aproveitemos de instrumentos de leitura e crítica atuais. A produção posterior do autor será parcimoniosamente considerada, sobretudo quando contribuir para uma apuração mais cuidadosa das condições de aparecimento do texto escrito, como é o caso, por exemplo, da reflexão ñPoesia de amanhãò, publicada em 1910, que ao projetar o futuro, aparenta, simultaneamente, ser uma elaboração sobre o que terá produzido nos anos passados. Outro texto a ser considerado é o seu livro de memórias, Quando eu era vivo, aparecido em 1942,

\footnotetext{
${ }^{1}$ Doutor em Letras pela Universidade Federal do Rio de Janeiro (UFRJ). É pesquisador sênior da Fundação Biblioteca Nacional (FBN). RJ, RJ, Brasil. E-mail: irineujcorrea@yahoo.com.br.
} 
alguns anos depois dele falecido, conforme sua orientação expressa: o que deixa registrado naquelas páginas contribui para delinear seu personagem autor. Nossa hipótese é a de que o texto poético tem potência para receber uma leitura sempre atualizada, sendo permissiva a gostos diversos ï leitor é autor, tradutor é traidor. Porém, tal característica não contorna a exigência de que as leituras possíveis estarão sempre pautadas no que o texto permita que se leia nele.

Os livros indicados são Peccados, de 1889, e Canções da decadencia, do mesmo ano. Cumpre aqui, um esclarecimento preliminar que termina numa retificação de informações. Algumas matérias jornalísticas e alguns estudos indicam como data de publicação do segundo título o ano de 1887, suposição tornada possível pela ausência de datação na folha de rosto e um comentário introdutório que dá conta de que a preparação dos poemas fora feita dois anos antes. O mesmo comentário, entretanto, fica nisso, não avançando em qualquer afirmação de que a sua publicação ocorrera naquele momento. Uma consulta cerrada aos periódicos de 1889 confirma a época do lançamento, como se pode ler na primeira página da Gazeta da Tarde, do Rio de Janeiro, de 19 de julho de 1889: ñorevemente, com o título Canções da decadência, sairá um livro de Medeiros e Albuquerque, talentoso autor dos Peccadosò. Antes disso, nada aparece na imprensa sobre o título supostamente lançado em 1887, nem uma simples nota, nem um comentário de seu amigo Araripe Jr. (1848-1911), que vinha se ocupando de conhecer o decadentismo e as novas correntes literárias europeias desde 1887. Igualmente, Wenceslau de Queirós que, em 1889, dedicará longa crítica ao livro, nada escreve sobre publicação anterior que seja da lavra do poeta, nem ele, nem qualquer outro comentarista. O esclarecimento final para solucionar a polêmica está em seu livro de memórias que, na página 64, da segunda edição, registra que os dois livros saíram na mesma época e o que fora escrito primeiro, Canções da decadência, fora publicado depois (ALBUQUERQUE, 1945, p. 64). Ou seja, até que um bibliófilo dê a conhecer o seu exemplar da suposta edição, vinda a lume em data anterior a 1889, os dados disponíveis atualmente permitem afirmar que esta revisão de datas é pertinente.

\section{A cena da Belle Époque e o personagem écrivain-dandy}

O período entre 1880 e 1920 vem sendo estudado de modo cada vez mais intenso, permitindo que se tome consciência da complexidade daquele momento. Sob uma superfície de glamour e arabescos, o período que se convencionou chamar de Belle Époque vem se 


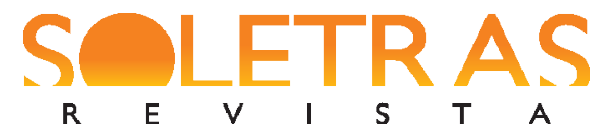

DOSSIÊï N. 34 ï 2017.2 Ï IRINEU EDUARDO JONES CORRÊA

revelando tempo de acontecimentos importantes e determinantes para o mundo social que lhe foi posterior. Libertam-se os escravos em 1888, começa o regime republicano em 1889, acontecem as Revoltas da Armada (1891 e 1893-1894), a Revolução Federalista (1893-1895) e a Guerra de Canudos (1896-1897). A passagem do século é palco da intensificação das lutas femininas por direitos sociais e emancipação política. Na primeira década do século XX acontecem as reformas urbanas na capital federal e a república se consolida. Na Europa, a ebulição sócio-política não é menos intensa, com acontecimentos como a Comuna de Paris, 1871, e a Revolução Russa, 1917, a nova industrialização, o êxodo rural, o crescimento acelerado das cidades, as grandes migrações intercontinentais.

O ambiente cultural não se compôs descolado dessa situação geral. O debate sobre as artes de modo geral se intensifica, com o surgimento de sucessivas novidades estéticas. Após um período mais ou menos confluente entre a weltanschauung romântica e o projeto imperial de nação em seus aspectos simbólicos, o campo literário foi se configurando relativamente independente $\ddot{i}$ acompanhando aqui a concepção de organização dos sistemas simbólicos do sociólogo Pierre Bourdieu (1992).

O enfrentamento mais marcante entre o romantismo e outras concepções estéticas ficou conhecido como a batalha do parnaso, acontecida no final da década de 70, com o Diário do Rio de Janeiro funcionando como sua principal tribuna. Em 1879, as novidades suscitam um longo comentário de Machado de Assis, que apresenta a nova geração, comentando a presença e a obra daqueles que elege como nomes promissores ï Fontoura Xavier, Teófilo Dias, Silvio Romero, Carvalho Junior, Afonso Celso Junior, Valentim Magalhães, Alberto de Oliveira, Lucio de Mendonça, Francisco de Castro, Ezequiel Freire, Múcio Teixeira ï e assinala especialmente a influência baudelairiana nessa produção (ASSIS, 1879).

Recenseando os acontecimentos literários de 1893, Araripe Jr. escreve uma série de artigos em jornal sobre a influência do ñdecadismo no Brasilò e posiciona o nome de Medeiros e Albuquerque como central para a presença do movimento no país ï seria ño primeiro homem de letras que se preocupou das suas manifestaçõesò. Segundo o relato, ele juntara uma coleção de livros e revistas com trabalhos dos melhores autores ñevolucionáriosò: Verlaine, Mallarmé, Jean Moreas, René Ghil, de St. Merril, Vieillé Griffin, Paul Adam, Vigner ñe outros sectários da revolta contra os naturalismosò. Todo o material teria chegado às mãos do articulista em 1897, emprestado pelo colecionador. E acrescenta que 
o amigo já fora interessado em psicologia experimental, política e, naquele momento, estava dedicado ao ocultismo (ARARIPE Jr., 1894, p. 306).

O autor também é apresentado por Lívio de Castro (1864-1890): muito jovem, quase imberbe, moço excêntrico, morador por um tempo do Chiado, versado em poesia tendo conquistado o automatismo do verso pela leitura,especialmente,de Guerra Junqueiro e Gomes Leal, publicou as primeiras poesias em Portugal, fotografou-se de barrete frígio, estudou filosofia com Silvio Romero no retorno ao Brasil.

Vestiu-se revolucionariamente, veste-se com originalidade. Suprimiu o que era excêntrico logo que apareceram muitos excêntricos ou pareceu-lhe comum, vulgar, vestir-se excentricamente[...] Roupas claras, justas ao corpo; veludo azul na gola do paletó; flor natural ou artificial na botoeira; longa e leve bengala com escudo de prata e a divisa, ñSe vis pacem para bellumò̀...] Ao excitante de que usa pede o efeito fisiológico sem pedir o saber: não é café nem álcool, é o grânulo decimétrico da estriquinina (CASTRO, 1889).

O personagem excêntrico não se descolaria de Medeiros e Albuquerque, mesmo quando já havia consolidado carreira de literato, filólogo e jornalista, participado do grupo fundador da Academia Brasileira de Letras e se tornara conferencista requisitado. A revista Fon-Fon, de 29 de junho de 1907, publica uma fotografia sua (figura 1), descrevendo-o como uma perfeita encarnação do dandismo. As referências a essa persona ainda circulariam após sua morte, ocorrida em 1934. Autores e livros, do Suplemento literário de A Manhã, publica, em 1942, uma foto antiga do poeta em trajes muçulmanos, imagem que se conjuga perfeitamente com trecho do comentário sobre um harém turco do poeta, que aparece no perfil sobre ele, escrito por Humberto de Campos e publicado no mesmo suplemento (CAMPOS, 1942, p. 87).

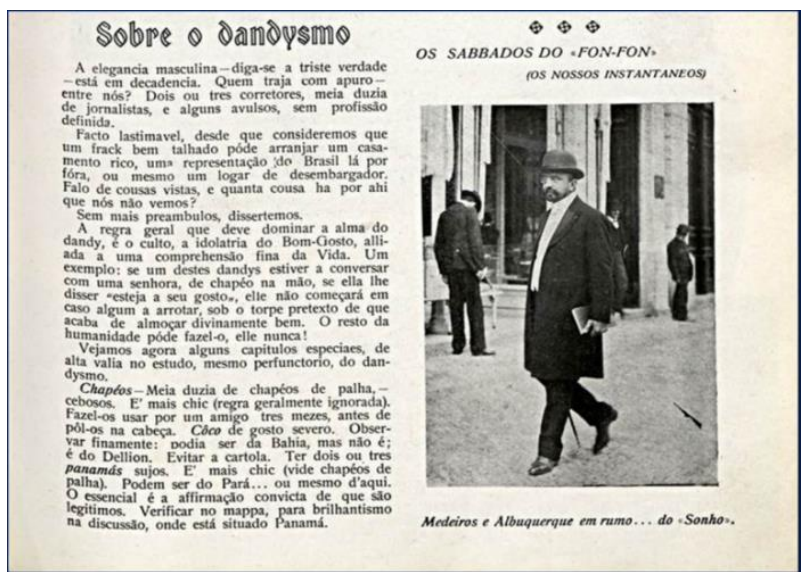

Fig. 1: Medeiros e Albuquerque na revista Fon-Fon, 29 de junho de 1907. Acervo FBN 
No mesmo ano, aparece o seu livro de memórias, no qual dedica capítulos inteiros a expor a sua experiência dandy: os amores donjuanescos em Paris, as experiências com o corpo e a mente, descrevendo desde experiências cirúrgicas e de mutilação, até delírios fármaco-determinados e a perda do filho. Lembranças e texto lavrados ao estilo da desumanidade de Des Esseintes, protagonista de À rebours (1884), escrito por J.-K. Huismans (1848-1907), romance reconhecido como uma espécie de bíblia herética do decadentismo (CORREA, 2006). Seria esse o personagem-autor que melhor serviria de referência aos dois livros, no léxico decadentista, um écrivain-dandy.

\title{
A estética, o desencanto e a tragédia decadentista
}

ñntroibo ad...ò é o poema escolhido para abrir a coletânea da primeira incursão do poeta no imaginário decadentista ï faz parte do livro Canções da decadência. Tem a inflexão de um manifesto, listando as intenções do sujeito-autor, que confluem para as propostas do movimento ao qual se integra. Poeta em começo de carreira, os ritos de iniciação são rigorosamente obedecidos, com a adoção de uma retórica contida quanto à qualidade dos versos que serão apresentados, embora anuncie o que seria um modo inteiramente novo de fazer poesia:

\author{
Estes versos que ora rimo \\ são canções da Decadência, \\ de uma idade de Ciência \\ em que a Poesia sem vida \\ jaz perdida.
}

Não têm assumptos sublimes,

Nem lavores caprichosos

ð pobres versos descuidosos, sem vida, em movimento, sem talento...

Cantei o que andam cantando, há cem mil anos, os poetas ð pobres, estultos patetas que andam buscando das formas puras normas.

(ALBUQUERQUE, 1889, p. 5-6).

ñProclamação decadenteò apresenta alguns dos pontos cardeais do imaginário decadentista: o pessimismo e os sentimentos de finitude dos tempos. O único brilho destoante dos tons abafadiços e depressivos seria oferecido pela poesia, única produção capaz de 
enfrentamento da cena caótica. Mas é o início do poema, a combinação de título e epígrafe, que chama a atenção pela invocação que faz às contradições daquele momento de transição. $\mathrm{O}$ título posiciona o poema no âmbito do movimento que se contrapunha ao grupo do parnaso. Logo na linha abaixo, todavia, aparece uma dedicatória a Olavo Bilac, nome significante do parnasianismo. Na próxima linha, entretanto, a obra é identificada como carta, datada em ñ20 de Florealò, oitavo mês do calendário da revolução francesa, de 1789, sugerindo uma subordinação ao imaginário burguês, que moldara o longo século XIX. Século ao fim do qual, o poema decadente reage, proclamando pessimismo, descrença e desalento diante do mundo resultante do predomínio dos valores burgueses. Uma reação que tem ñVerlaine profeta e

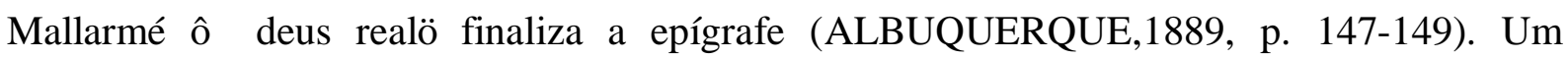
sentimento reativo que está nas origens do movimento: ñenfadados por essa literatura venal, estéril e terra a terra [...] e que faz as delícias do burguês sem alma, lançamos um formidável grito de alarme [...]ò, conforme anunciara Anatole Bajú, em 1887 (BAJÚ, 1887, Apud MORETTO, 1989, p. 89-112).

Vários signos do desalento e pessimismo são trabalhados em ñVersos sobre Edgar Poeò, homenagem à obra que, recepcionada por Baudelaire (1821-1867), adquiriu a potência de modelo para a poesia da modernidade. Nas duas últimas estrofes, todavia, a invocação ao autor americano permitiria que se leia uma dose de idealização do personagem que invoca, quase numa expressão romântica:

Si houvesse, como tu, dez criadores d'essas visões nevróticas e ardentes, da Insânia nos sublimes esplendores todos nós rolaríamos contentes!

Grande Poe, a Loucura, que matou-te, há de empolgar-me o cérebro algum dia:

ð tu e eu, nós iremos da amplidão contra os sonhos falazes da Razão semeando a Ironia!

(MEDEIROS E ALBUQUERQUE, 1889, p. 83-86).

Ao lado dessa ocorrência, a cuidadosa metrificação em decassílabos aponta para compromissos formais parnasianos. Estaria colocada uma sucessão de influências que posicionaria o longo poema em uma posição de obra representativa das transições do período, como acontece nos versos de ñProclamação decadenteò, comentados acima. Um lugar que, 
aliás, é bem adequado à obra de Edgar Allan Poe (1809-1849), escrita em plena vigência da estética romântica e disputada por mais de um grupo entre os que lhe foram posteriores.

Os poemas de Peccados são saudados como de evidente influência da filosofia de Schopenhauer, num viés de extração verlainiana, explica Wenceslau de Queiroz (1863-1921), poeta que já adquirira fama como baudelairiano, crítico com espaço cativo na imprensa paulista, cujas opiniões repercutiam na capital federal (QUEIROZ, 1889, Apud DECADISMO, 1980, p. 165-169). Esta marca aparece explícita na epígrafe do ñSoneto decadenteò, que transcreve dois versos da ñArt poètiqueò, de Verlaine (1844-1896), poema disputado por decadentistas e por simbolistas, enquanto determinante para seus modelos de poesia Ï Car nous voulons la nuance encore,/ Pas la couleur, rien que la nuance. A ideia de desânimo e desagregação do sujeito é metaforizada pelas imagens opacas e as luzes oblíquas dos versos, como se atendessem à determinação de nada de cores, apenas nuances indicadas na epígrafe, ao mesmo tempo em que elas parecem moldadas em diálogo com as paisagens tristes dos ñPoémes saturniensò(1866), do poeta francês.

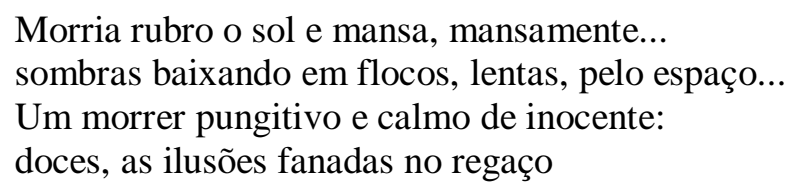

(ALBUQUERQUE, 1889, p. 46).

O mesmo tom pessimista aparecia já nos primeiros versos, do primeiro poema do livro ñPara o nadaò. Sempre ao Bem excede a escura/ projeção negra do Mal!/ O Gênio, o Crime e a Loucura/ são faces de um só cristal [...] (ALBUQUERQUE, 1889, p. 1-2). O destino do homem está definido neles, nada escapará ao mal, à loucura, ao crime. O poema realiza uma reflexão sem objeto determinado, finalizando com uma invocação ao Nirvana, destino do homem e do universo, na linha da assimilação das filosofias orientais propostas pelo filósofo alemão. No estatuto proposto por ele, nirvana seria um estado de paz sem fim, almejado pelo homem, mas inalcançável em sua plenitude. A reflexão sobre a inexorabilidade da decadência como destino final do ser reaparece em outro poema,ñNirvanaò. O sujeito poético confronta o ente supremo, numa queixa que não é atendida ï E pois que o teu olhar/Senhor, não vem, não desce/e como um sol brilhante não aquece,/a alma, em gelos de dúvida, a hesitar (ALBUQUERQUE, 1889, p. 38-39). Nessa situação não há deus, beleza, bem, futuro, verdade e, ao fim, a natureza inteira se aniquilará. 
No continuum entre as duas peças, percebe-se uma diferença nos procedimentos formais, que não parece aleatória. O primeiro poema, no qual o destino é tratado como irresistível, não havendo mágoa ou revolta, convergindo para esse estado sentimental, a composição é igualmente regular, montada em oito quartetos, de versos heptassílabos. No segundo, há uma queixa ao ente supremo, queixa que não é atendida, resultando numa revolta. Neste caso, foi empregada uma forte variação formal: os versos das duas primeiras estrofes de cada quarteto têm seis sílabas e os versos das duas últimas têm 10 sílabas, resultando num efeito visual convergente com o desassossego do texto. Uma relação forma e escrita que convergem para uma unidade de conteúdo altamente elaborada e muito buscada pela poesia modernista.

A opção pelo ideário decadentista avança em outra composição trabalhada no mesmo padrão schopenhaueriano. Os versos decassílabos de ñRespostaò propõem desmistificar a estética sentimentalista e idealista. Na esteira dos franceses, o soneto anota a desilusão com a ideia de natureza grande e bela dos românticos, ñudo na imensa Natureza/é simplesmente uma ilusão terrívelò (ALBUQUERQUE, 1889, p. 32). O desencanto e o pessimismo do último terceto tendem ao absoluto, em um mundo em que a própria esperança está arruinada, não restando ao artista sequer ño prantoò nenhum sentimento além da constatação dessa tragédia.

A tragédia como temática é reafirmada no soneto ñQuadro de Goyaò (ALBUQUERQUE, 1889, p. 145), conforme propusera Baudelaire (1821-1867), no longo ñLes pharesò (1857), versos em que assinalou que o pintor espanhol seria uma das sentinelas que gritariam a denúncia das desgraças humanas. No que se refere ao trágico que os versos invocam, o eu poético se coloca frente a frente com a finitude e o vazio da vida, portanto, com a tragédia do fim da idealização das coisas do mundo. Como em outras composições, entretanto, Medeiros e Albuquerque busca na forma corresponder ao que o texto propõe. As três estrofes, cada uma com quatro versos, permitem a sugestão de o poema estar estruturado numa espécie de tríptico, uma solução pictórica não incomum, reforçando as estreitas relações entre as artes poética e pictural e reforçando a hipótese do diálogo com o poema francês, reconhecidamente uma homenagem do grande crítico de arte que foi Baudelaire, aos grandes pintores que cita e à sua arte.

O afastamento do ideário romântico, citado anteriormente, continua em ñVirgens profanadasò, poema em que o tema da amada virgem e pura que, morta, se tornava inalcançável para o sujeito poético, recebe outro tratamento na inflexão decadentista: agora 
ela será profanada ï manda a vetusta crença soberana/ que alguém noive esse corpo, que arrefece terrível (ALBUQUERQUE, 1889, p. 150). Embora, no terceto final, haja uma modulação sublimada para o ato, ela acontece no sentido da semelhança divergente entre as composições decadentes e românticas: enquanto estéticas gêmeas sinistras, em uma o sublime é puro, mesmo quando altamente erótico, na outra ele é doentio e perverso, mesmo quando sublimado (COUTINHO, 2014).

\section{$O$ artista moderno e as flores do mal}

ñDernier amourò é um soneto escrito em francês, opção de língua vez por outra entendida como mera futilidade, o que atestaria uma espécie de subordinação colonizada. No âmbito do esteticismo decadente, porém, ela adquire um sentido mais complexo, aparecendo como um produto do diálogo direto com as fontes primeiras do movimento. $\mathrm{O}$ artista moderno baudelairiano renunciaria a um diálogo com as massas, divergindo da proposta dos parnasianos, que até concurso para eleição do poeta do ano fizeram. Os decadentistas faziam poesia em léxico difícil, procurando vocábulos pouco usuais e metáforas complicadas. Produzindo para os raros, nada mais lógico do que escrever em francês, língua da cultura mais elevada da época. Seria através dessa composição sofisticada que o écrivain dandy tropical, que já proclamara sua filiação estética em tantos outros poemas, apresenta seu potencial em definitivo, não apenas na leitura do texto decadente no original, mas na capacidade de escrever naquele dialeto. Munido desse instrumento, ele tematiza o feminino num sentido radical, sonhando com ñuma mulher impecavelmente belaò, de carnalidade impossível de ser retratada até mesmo pelo supremo escultor, Fídias. Ao registrar essa impossibilidade, parece propor uma elaboração original sobre a temática da estátua, comum na poesia de modo geral, presente nas composições decadentes, pois, ao abrir mão da metáfora, é como se propusesse uma presença que não se realiza $\ddot{i}$ apenas o feminino permanece disponível ao leitor. Um feminino com potência bastante para colocar em risco quem dela se aproxima. O prazer é anunciado como o derradeiro, equivalendo a uma experiência mortal, mesmo que seja o desmaio do gozo, é a chave de ouro do poema ï je sentirai la Mort dans cette pâmoison... (ALBUQUERQUE, 1889, p. 146).

O tema do feminino está presente nos versos de ñA uma pecadoraò, do livro Canções da decadência. Neles o écrivain dandy se dirige às mulheres perdidas e pervertidas, seguindo as marcações propostas em Les fleurs du mal (1857), de Baudelaire. Ele reconhece a 
existência das virgens e castas, mas denuncia a sensualidade e a luxúria contidas, apenas imperfeitamente, pelas convenções moralistas. Identifica-se e dá estatuto de verdade humana ao drama daquelas outras que ganham a vida nas ruas e nas camas de quem lhes paga. Realizando uma elaboração convergente com a do poema de Baudelaire, o trabalho aqui traz para o plano poético a beleza do mal, convocando metáforas românticas, sublimes e grotescas ï no contraste discutido no prefácio do romance Cromwell (1827), por Victor Hugo (18021885).

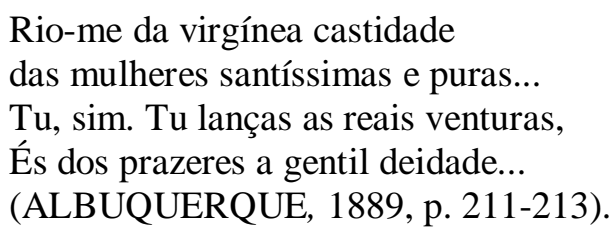

Um exercício de reflexão constitui ñNoites de enfadoò (ALBUQUERQUE, 1889, p. 8991). O matiz é pessimista: o sujeito poético circula por uma cidade envolta na penumbra das horas noturnas e das ruínas. As memórias de um passado hipotético apenas reafirmam o signo perverso e decadente do cenário e dos acontecimentos. Ao atualizar a cena, trazendo-a para o presente da escritura, o personagem se revela $\ddot{i}$ um boêmio, um flanêur que circula entre prostitutas, juventude perdida, bêbados e assassinos, vidas dominadas pelo álcool e pelos vícios. Verso a verso, estrofe a estrofe, a cena se encaminha para chancelar o tédio absoluto grafado em maiúscula, o supremo sentimento decadentista. A chave de ouro, entretanto, interpõe uma interrogação sobre a inexorabilidade deste spleen, que fica sem resposta ï uma prerrogativa do poeta.

No percurso que faz pelos temas radicais do decadentismo, a obra de Medeiros e Albuquerque ergue um brinde ao absinto. Droga preferencial da boemia finissecular, flagrada nas mãos de uma dançarina de cabaré por Toulouse Lautrec (1864-1901), bebida que está posta diante de um Verlaine retratado nos fundos de um bar miserável, ela se derrama pelos oito quartetos de ñSublime dísticoò para erotizar as dores de algumas das grandes tragédias engendradas pelo amor na literatura. Exalta as potências viciosas de cada uma delas e, num acento fortemente baudelairiano, exalta as desgraças e baixezas humanas através das primícias da poesia. Afirma as qualidades inebriantes e alucinógenas da bebida, apresentandoa como solução de toda a dor e desgraça do mundo, fechando o poema com uma invocação decadentista em absoluto. 
Quero-a! Desejo-a!... Às bordas dessa taça, bem contrário ao de Dante:ð mote horrendo que se escreva a fulgir: ñAQUI, BEBENDO, DEIXA-SE TODA A DOR! TODA A DESGRAÇA! Ò (ALBUQUERQUE, 1889, p. 109-110).

ñMoços pálidosò (ALBUQUERQUE, 1889, p. 47) é outro poema que visita os temas tabus de seu tempo, enfocando o erotismo e o desejo resolvidos na intimidade solitária dos leitos. Ao final, na última estrofe, o sujeito autor suaviza o movimento, deixando em suspenso o que se encaminhava para uma explicitação do ato de masturbação e projeta nos sonhos noivados fantásticos. O estado onírico é um dos grandes temas filosóficos e científicos da época, em 1900, Sigmund Freud (1856-1939) lançaria A interpretação dos sonhos, revelando os segredos daquele estado físico-mental. Trata-se de assunto preferencial no imaginário decadentista, sempre interrogativo sobre os estados alterados de consciência.

A exploração dos sentimentos recalcados também é o mote do poema ñQuestão de estéticaò, que tematiza o desvelamento do objeto desejado e a ausência de nobreza e sublimação na busca dessa realização, mesmo que seja nas instâncias poéticas: ñque não tens, animando-te o portento/ da imperceptível Forma triunfal, /nem um nobre e sublime pensamento!ò (ALBUQUERQUE, 1889, p. 33). Interessante notar como os signos de materialidade corpórea se apresentam discretos, apenas os semas veia, no segundo verso da segunda estrofe, e corpo, no primeiro da terceira, no mais, somente os sentidos são convocados na composição, parecendo repetir a fórmula de renúncia à metáfora da estátua, que o poeta experimentou em ñDernier amourò, visto acima.

ñDomadoresòé um exercício metalinguístico sobre o ofício do poeta finessecular:

esta fera: $ठ$ a Palavra, que carece para acalmar seus Ímpetos insanos ð seiva e sangue de cérebros humanos (ALBUQUERQUE, 1889, p. 46).

É uma solução que inverte a proposta de ñLâlbatrosò, de Baudelaire, poema no qual o poeta é apresentado através de um contraste entre a beleza e grandeza de sua atividade e as dificuldades e limitações de sua vida entre os homens comuns. Ao oferecer a palavra domador como metáfora para poeta, instiga uma polifonia divergente para o significante. Domador encerra uma condição de dominar a dor. A escolha dialoga, também, com a identidade de leão,conforme proposta para o dandy no texto baudelairiano de 1863, ou seja, o artista 
moderno tem por função domar a fera que identifica a si próprio. Trata-se de um exercício de diálogos complexos com alguns dos textos seminais da modernidade literária.

O tema da ñFeraò (ALBUQUERQUE, 1889, p. 61) e de seu domador retorna neste soneto, explorando as tensões entre a metáfora baudelairiana para o artista da vida moderna, a fera, e aquele que a controlaria, o domador. Faz dos dois personagens um duplo com o qual explora os limites dos sentimentos ï o medo, o pavor e, na chave de ouro, a denegação que revela a possibilidade da existência de um coração no peito do personagem. A denegação, trabalho da psiquê identificada por Sigmund Freud como a negação sistemática do que está sendo constantemente revelado, é exercício constituinte de toda a psicologia de Des Esseintes, o aristocrata protagonista de À rebours, de J.-K. Huysmans, uma psiqué sempre exposta ao leitor, embora mantida oculta aos pares do personagem nas cenas do romance.

\section{Um lugar na cena da modernidade}

A cena da modernidade em que se insere o debate proposto pelos decadentistas é aquela anunciada por Baudelaire, desde Le salon, de 1846, quando ainda se refere ao romantismo como a expressão mais recente e contemporânea para a beleza. Ele se mostra completamente extasiado com os trabalhos de Delacroix ï cores, nuances, dramaticidade. A projeção de interesse pelo novo se reafirma nos textos sobre o salão de 1859 , quando faz um longo comentário sobre o artista moderno e, noutro trecho, escreve sobre o público moderno. A opção pela renovação se define completamente com as publicações dos textos sobre o pintor da vida moderna, consagrado como o texto fundador do novo tempo e seus modos de viver e fazer arte por boa parte da historiografia literária (BAUDELAIRE, 1846, 1859, 1863).

A modernidade baudelairiana seria

[...] a possibilidade paradoxal de ir além do fluxo da história através da consciência da historicidade em seu imediatismo mais concreto, em sua atualidade. Esteticamente falando, a "eterna metade da beleza" (que consiste nas leis mais gerais da arte) pode ser trazida para uma vida fugaz (ou vida após a morte) apenas através da experiência da beleza moderna. Por sua vez, a beleza moderna está incluída no reino transhistórico dos valores ï torna-se "antiguidade" ï mas apenas ao preço de renunciar a qualquer reivindicação para servir como modelo ou um exemplo para futuros artistas. Separado da tradição (no sentido de um conjunto de obras e procedimentos a serem imitados), a criação artística torna-se uma aventura e um drama em que o artista não tem aliado exceto a imaginação (CALINESCU, 1996, p. 48-49). ${ }^{2}$

\footnotetext{
${ }^{2}$ Tradução nossa em todos as ocorrências, exceto quando registrado especificamente. 
Em torno desse ideário um grupo de literatos produziria uma obra que desestabilizaria o status quo do campo, chocando o público e seus pares, inclusive aqueles empenhados em trabalhar novas propostas estéticas. Lançando seu olhar ao grotesco e ao marginal, eles trouxeram para dentro da arte literária a doença, a perversão, a maldade. É verdade que estes temas sempre estiveram na literatura, nas tragédias, nas comédias, na pornografia, tratadas, entretanto, como caracteres baixos, a serem superados pelas virtudes e pelo bem. Na estética desse grupo, a situação se altera completamente, essa temática adquire o lugar principal nas composições, trabalhadas como objeto final da obra de arte, respondendo aos sentimentos de pessimismo e de ceticismo em relação à capacidade da humanidade de superar as contradições de um mundo e uma sociedade que se moldava segundo o vitorioso pensamento burguês e seu tecnicismo, cientificismo e moralismo.

Em plena vigência de uma produção literária pautada em modelos estéticos de inspiração clássica, de constante busca da beleza equilibrada e sublime e de cultivo estremado da forma, por um grupo muito bem-sucedido de público e crítica, que se autodenominaria parnasiano, aparece um livro com um nome paradoxal, Les fleurs $d u$ mal $̈$ as flores do mal. O ano era o de 1857. As flores apresentadas naquelas páginas eram as prostitutas, as viciadas e as tuberculosas dos lupanares parisienses, mas, não apenas elas, as tais flores significavam também todos os sentimentos e comportamentos degradantes que um sujeito poeta seria capaz de escrever em forma de poesias. O autor era o mesmo Baudelaire, crítico de arte que falava sobre a modernidade. A historiografia registra que ele foi preso, a edição censurada, os poemas execrados pela crítica, mas a coletânea foi um enorme sucesso. Novas edições, acrescidas de novos poemas, seriam publicadas sem preocupações com a censura ou com a autocensura. Em 1868, Théophile Gautier (1811-1872), o consagrado poeta, líder do grupo parnasiano, escreveria o prefácio de uma nova edição do livro, reconhecendo as qualidades originais e inovadoras do trabalho. Menos de uma década depois, a temática e o estilo já inocularam toda uma geração de autores, em especial aqueles fora dos circuitos mais importantes. Era um grupo cuja esquisitice estética e comportamental inspirou uma série de apelidos debochados: vibrants, modernistes, sensationnistes, impressionistes, nouvelle école, nouveau Parnasse, decadenticulets. Tão excêntrica era a tribo que, em pleno e intenso confronto com os opositores de seu estilo, ela assumiu o apelido em definitivo, decadentes (MORETTO, 1989, 25-27e CALINESCU, 1996, 167-170). 
São os trabalhos desse grupo que Medeiros e Albuquerque reúne, traz da Europa e oferece aos amigos para leitura. Sem que se conheça a lista exata de obras que formariam a coleção, os comentários de Araripe Jr. permitem recuperar o que circularia nos círculos letrados até 1884, ano do retorno do colecionador. Para oferecer um quadro do possível universo de leituras do poeta, serão incluídas nesse rol obras e escritos até 1888, ano anterior ao lançamento de seus livros, a suposição que ele terá continuado a receber informações e publicações europeias.

Stéphane Mallarmé (1842-1898) envia o poema ñHérodiadeò para publicação em 1869, ñPlainte dôutommò é publicado em 75 e Lâaprès midi dôım faune aparece em edição de luxo em 76. Paul Verlaine (1844-1896) publica Fêtes galantes em 1869, La Bonne Chanson em 70, Romances sans paroles em 74, Sagesse em 80 e Jadis et Naguère em 84. Entre os poemas deste último livro está ñLangueurò, poema seminal para o esteticismo decadente. Na crítica, o poeta havia publicado Les poètes maudits em 1883, que apareceria em nova e mais alentada edição no ano seguinte. No mesmo 1884, aparecem os versos de ñLârt poètiqueò, recepcionado como uma declaração de princípios do esteticismo, e quatro anos depois, em 1888, Lettre au Décadente. Arthur Rimbaud (1854-1891), referido como deus na epígrafe de ñProclamação decadenteò, publica ñUne saison en enferò e ñAlchimie du verbeò, ambos em 1873. Jean Richepin (1849-1926), cujos versos de Les blasphèmes, de 1884, foram lidos na viagem de retorno ao país, é o autor de La chanson des gueux, violentíssimo libelo de crítica social em versos, publicado em 1876 e, depois, em 1881, com os poemas que faltaram na primeira edição. Seriam especialmente os versos de Les caresses, de 1877, que inspirariam a carnalidade de Canções da decadência, observa Antonio Arnoni Prado (2003, p. XXIX).

Jean Moréas publica, sob inspiração verlainiana, Les Syrtes, em 1884. Mais tarde, em 1886, escreveria o artigo Les symbolistes, no jornal Le Figaro, abrindo caminho para mitigar o radicalismo da estética decadentista. Fora da lista de Araripe Jr., dois nomes seriam incontornáveis entre os "sectários da revolta contra os naturalismosò. $\mathrm{O}$ autor de Theorie de la decadence, Paul Bourget (1852-1935), obra editada em 1881, considerada como uma das bases teóricas do movimento, ao lado dos textos filosóficos de Arthur Schopenhauer (17881860). O outro nome é o de Anatole Bajú (1861-1903), que não era poeta, mas foi o grande agitador do movimento, com os artigos La vérité sur lấcole decadente pour un Bourgeois lettré e Lốcole décadente, ambos de 1887. Das revistas que estariam na bagagem de qualquer 
poeta interessado em novas ideias não faltariam LốHidropathes, editada entre 1879 e 1880 e Le chat noir, que circulou entre 1882 e 1889.

Entre os autores portugueses, Medeiros e Albuquerque cita nominalmente a leitura de Gomes Leal (1848-1921), que publicou A Traição e O Herege, em 1881, e O Anti-Christo, 1884-1886. Embora não comentado no livro de memórias, o poeta baudelairiano Carlos Fradique Mendes, heterônimo criado por Antero de Quental e Eça de Queirós, teve publicado peças suas nas décadas de 70 e 80 , sendo, portanto, factível que fosse do conhecimento do jovem estudante brasileiro em sua estada em Lisboa.

Estariam em torno de títulos como esses as bases da poesia do écrivain-dandy de Peccados e de Canções da decadência,títulos de evidente pretensão de integrar o debate estético de seu tempo, com clara preferência por se posicionar na perspectiva do grupo mais radical entre eles. Uma detalhada cartografia do diálogo de sua poesia com os poetas e a crítica de seu tempo, elaborada por Arnoni Prado, corroboraria aquela perspectiva (PRADO, 2003, p. XV-XXXVIII).O diálogo com a poesia de Olavo Bilac, Luiz Delfino, Raimundo Correia, Alberto de Oliveira e Teófilo Dias ao mesmo tempo que expõe a obra a comparações não necessariamente favoráveis, é também procedimento próprio do grupo estético que promove uma releitura e uma apropriação dos temas caros àqueles poetas precedentes. Ritual que é plenamente assumido nas epígrafes, dedicatórias, citações e paráfrases. Como, aliás, é praxe nas sucessivas transformações e rupturas promovidas por cada novo grupo de poetas, caso, por exemplo, da paráfrase sobre versos de Richepin, proposta por Raimundo Correia, em Versos e versões, de 1887. E como, antes dos parnasianos, fizeram os românticos. A invenção do passado ou a imitação e meta-imitação dos Antigos, ainda não foi elaborada como a importância do tema está a exigir (MARQUES, 2004, p. 9-16), instrumentalizando de modo mais consistente o debate sobre a questão das rupturas e transformações insistentemente invocadas desde a modernidade, inclusive pelos decadentistas.

A polêmica que travou com Silvio Romero é um confronto entre duas concepções diversas sobre o fazer literário. O mestre defendia critérios científicos de análise da obra literária, segundo parâmetros que ele mesmo chama de naturalistas, pautados pelos métodos e processos da escola das ciências sociais francesa do século XIX. Seria com essa bagagem que elaboraria a sua História da literatura brasileira, com primeira edição em 1888. Seu aluno de filosofia, Medeiros e Albuquerque, tem outros parâmetros, acredita na criação, liberta de critérios de metrificação rígidos: a emoção, a intenção do autor deve prevalecer, o mais é 
mero instrumento para um bom resultado de seu trabalho. Continuará defendendo esta ideia em 1910, do lugar de homem de letras importante, quadro fundador da Academia de Letras. Naquele 1889, o poeta empreende o contraditório à corrente cientificista de crítica e aos modelos parnasianos de versificação com poesia. Em ñHino ao risoò, confessa, desafiadoramente:

A Sylvio Romero, amigo e mestre

Eu sou filho deste tempo insano em que tudo na dúvida se agita e em nevroses histéricas palpita o triste louco pensamento humano;

alegremente minha parte aceito nas ruínas fatais da Decadência e até mesmo do brilho da Ciência folgo, zombo, sorrio satisfeito...

Pois que a Forma é mentira e tudo passa na caudal portentosa da Matéria, ï esqueçamos os gritos da Miséria! ï os sinistro gemidos da Desgraça!

O que faremos?!

Vendo o grande Nada do Cosmos que se estorce em vãos gemidos, na Morte rolaremos, envolvidos na final, na suprema gargalhada! (ALBUQUERQUE, 1889, p. 51-58).

O poema é uma declaração de existência do poeta decadentista, ao lado de ñ́ntroibo ad...ò e ñDeclaração decadenteò. Seu aspecto original é a epígrafe dedicatória, que remete a seu preceptor. A anotação desmistifica a ideia de grupos fechados e relações distanciadas na medida em que os agentes do campo literário se filiavam a diferentes estéticas. Uma suposição informada, talvez, pela linguagem dos manifestos inaugurais de cada grupo que têm como modelagem retórica a desqualificação do ideário que pretendiam superar. Suposição que se reforçava pela postura, eventualmente, agressiva de algumas críticas e eventuais desavenças pessoais. Ao contrário disso, não se pode esquecer que a mais revolucionária proposição estética sempre renderá homenagens àquelas que lhe foi anterior, justamente ao fazer a crítica que a constituirá.

O pertencimento à tribo decadentista é duplamente exigente, tribo aqui no sentido proposto pela análise do discurso, quanto ao grupo que se forma no sentido de construir e 
defender um posicionamento (MAINGUENEAU, 2006). O artista deverá corresponder, em seus aspectos simbólicos, ao écrivain-dandy, ao autor marginal ï drogas, crimes, miséria marcam a vida e a morte de nomes como Verlaine, o chefe do grupo, ou o de Rimbaud, de vida curta e errante. A ligação intensa entre o movimento e um sentimento de pessimismo em relação à capacidade de humanidade de fugir da corrupção moral e do aniquilamento social dá um caráter tumoral ao movimento, para usar o termo de Claudio Iglesias (2014, p. 16). Suas características radicais, que corresponderiam a um modelo de atuação política anarquista, naquilo que o anarquismo enseja de antiburguês, não teria espaço no mundo dominado hegemonicamente por aqueles, não haveria espaço para sua permanência nem de modo exclusivo, nem por um período muito longo. A reação ao decadentismo partiu das próprias hostes, com Jean Moréas, poeta que iniciou carreira escrevendo sob inspiração baudelairiana, publicando artigo defendendo explicitamente o abandono das referências oferecidas pelo nome adotado pelo grupo, em favor do mitigado epíteto ñsimbolistaò. No Brasil, a estética decadentista conviveu e dialogou com o parnasianismo que, por sua vez, permaneceu contagiando a poesia ao logo do século XX.

No caso de nosso personagem, o jovem e irrequieto poeta cederia lugar ao jornalista, cidadão engajado no serviço público, conferencista requisitado, crítico literário, poeta, contista e cronista, memorialista, filólogo, autor da reforma ortográfica de 1907.

Huismans contou para um amigo que as perversões de seu personagem Des Esseintes eram mistificações, não poderiam ser tomadas como parâmetro de conduta. No livro de memórias do homem público Medeiros e Albuquerque, está registrado que a experiência com absinto, descrita em ñSublime dísticoò, era ñuma forma de espírito revolucionário, que procurava todos os modos para manifestar-seò (ALBUQUERQUE, 1945, p. 66). A separação entre o cidadão e o sujeito poético dandy que se integra ao poema, tornada explícita através da afirmação, é a evidente reivindicação feita pelo autor, que generosamente oferece os parâmetros mais seguros para uma aproximação a ser feita aos versos do poeta, ao mundo constituído pelo discurso literário que aparece na convergência dos rituais da cena literária de seu tempo. Ela não impede desde a fruição mais sentimental do que houver entre o sublime e o trágico no poema, até a elaboração mais complexa teoricamente que se pretenda sobre ele. Apenas não há como ser descartada. 


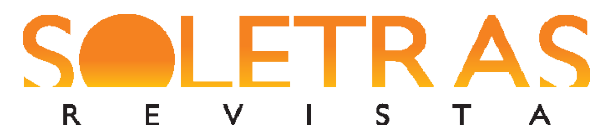

DOSSIÊï N. 34 ï 2017.2 Ï IRINEU EDUARDO JONES CORRÊA

\section{Referências}

ALBUQUERQUE, José Joaquim Medeiros e. Canções da decadencia. Porto Alegre: Carlos Pinto \& Cia, 1889a. . Peccados:1887-1888. Rio de Janeiro: Typ. da Papelaria Parisiense, 1889b.

.Poesia do amanhã. In Revista da Academia Brasileira de Letras, vol. 1, 1910. http://www.academia.org.br/academicos/medeiros-e-albuquerque/textos-escolhidos. Acesso em 10/06/2017.

.Quando eu era vivo... . 2. ed.Rio de Janeiro: Editora da Livraria do Globo, 1945.

AMARAL. Glória Carneiro do. Aclimatando Baudelaire. São Paulo: Annablume, 1996.

ARARIPE J., T. A. Retrospecto litterario do anno de 1893. Continuação ï IV. A SEMANA tomo V, no 39, 28/04/1894, p. 306.

ASSIS, Machado de. A nova geração. In __. Obra Completa de Machado de Assis. Vol. III. Rio de Janeiro: Nova Aguilar, 1994. Publicado originalmente na Revista Brasileira, vol. II, dezembro de 1879.

BAJÚ, Anatole. Lấcole decadente. Paris: Léon Vanier, Editeurs des Décadents, 1887. In: MORETTO, Fúlvia. Caminhos do decadentismo francês. São Paulo: Perspectiva, 1989, p.89112.

BAUDELAIRE, Charles. Le peintre de la vie moderne (1863). In Écrits sur lâurt. Paris: Le Livre de Poche, 1999, p. 503-552.

.Le salon de 1846. In . Écrits sur lôart. Paris: Le Livre de Poche, 1999, p. 135-242.

.Le salon de 1859. In . Écrits sur lâart. Paris: Le Livre de Poche, 1999, p. 349-446.

BOURDIEU, Pierre. As regras da arte. Trad. Maria Lucia Machado. São Paulo: Companhia das Letras, 1996.

.Les règles de lârrt: gênese et structure du champ littéraire.Paris: Seuil, 1992.

.Os usos sociais da ciência: por uma sociologia clínica do campo científico. Texto revisto pelo autor com a colaboração de Patrick Champagne e Etienne Londais. Trad. Denise B. Catani.SãoPaulo: Editora da UNESP, 2004.

CALINESCU, Mattei. Five faces of modernity: Modernism Avant-Garde Decadence Kitsch Postmodernism. Durham, NC: Duke University Press, 1996.

CAMPOS, Humberto. Perfil de Medeiros e Albuquerque. Suplemento Literário de A Manhã. Publicado semanalmente, direção de Múcio Leão. n. 6, vol. IV, ano III, 14/2/1943, p. 87.

CASTRO, Lívio de. O homem. NOVIDADES. 15 de abril de 1889, Anno III, $\mathrm{n}^{\mathbf{o}} 364$. In Decadismo e simbolismo no Brasil: critica e poética. Sel. e apres. Cassiana Lacerda Carollo. Rio de Janeiro; Brasília: Livros Técnicos e Científicos; INL, 1980-1981.

CORRÊA, I. E.J. O dandy no diário de Medeiros e Albuquerque: o texto como estilo de existir. In: COUTINHO, Luiz Edmundo B; MUCCI, Latuf Isaias. Dândis, estetas e sibaritas. Rio de Janeiro: Confraria dos Ventos; Faculdade de Letras da UFRJ, 2006, p. 148-162. 
COUTINHO, Luiz E. Bouças. Romantismo/decadentismo: gêmeos sinistros. In $A$ sedução do texto: arabescos, paradoxos e simulacros. Rio de Janeiro: Confraria dos Ventos, 2014, p. 169-177.

IGLESIAS, Claudio. Antología del decadentismo ï 1880-1900. Buenos Aires: Caja Negra, 2014.

JURT, Joseph. La teoría de los campos desde el prisma de la literatura. Trad. María Victoria López. In: Revista del Museo de Antropología 8 (1): 225-232, 2015 / IDACOR-CONICET / Facultad de Filosofía y Humanidades ï Universidad Nacional de Córdoba ï Argentina.

MARQUES, Luis. Apresentação: imitação e meta-imitação dos antigos. In MARQUES, L. et alli. A constituição da tradição clássica. São Paulo: Hedra,2004, p. 9-16.

MAINGEUNEAU, Dominique. Discurso literário. Tradução Adail Sobral. São Paulo: Contexto, 2006.

MORETTO, Fúlvia. Caminhos do decadentismo francês. São Paulo: Perspectiva, 1989.

MURICY, Andrade. Panorama do movimento simbolista brasileiro. 2.ed. São Paulo, 1987, 2 vols.

PRADO, Antonio Arnoni. Introdução. In: ALBUQUERQUE, Medeiros. Canções da decadência e outros poemas. Introdução, organização e fixação do texto A. A. Prado. São Paulo: Martins Fontes, 2003, p. XV-XXXVIII.

QUEIROZ, Wenceslau de. Páginas volantes. CORREIO PAULISTANO. 4 e 18 de julho de 1890. In Decadismo e simbolismo no Brasil: critica e poética. Seleção e apresentação Cassiana Lacerda Carollo. 1a ed. Rio de Janeiro; Brasília: Livros Técnicos e Científicos: Instituto Nacional do Livro, 1980-1981.

\title{
Medeiros de Albuquerqueâ eccentric poetry: decadentism in the Academy
}

\begin{abstract}
This work studies the presence of decadent poetry in the Brazilian literary field, with a special focus on the work of José Joaquim de Medeiros e Albuquerque (1867-1934), a young poet who publishes his two books under 23 years of age. His poems are little known, and when commented they are treated as inferior literature, although the author was a well-known journalist, lecturer, literary critic, short story writer and chronicler, memoirist, philologist, author of the 1907 orthographic reform and a member of the founding group of the Brazilian Academy of Letters. The hypothesis is that this reception does not consider the rhetoric and rituals of the time and of the decadent model. When we reevaluate his work considering these parameters, his poems acquire larger dimensions, revealing a work perfectly engaged with its time and the decadent esthetics. The reading and synthesis proposed here are based on the discourse analysis, as developed by Dominique Maingueneau, and on the studies about the organization of the symbolic systems by Pierre Bourdieu.
\end{abstract}

Keywords: Belle Époque. Decadentism. Aestheticism. Poem. Tribe.

Recebido em: 30 de setembro de 2017.

Aprovado em: 07 de novembro de 2017. 